\title{
RESENHA DE O IMAGINÁRIO TRÁGICO DE MACHADO DE ASSIS: ELEMENTOS PARA UMA PEDAGOGIA DA ESCOLHA, DE ROGÉRIO DE ALMEIDA
}

\author{
Review of O Imaginário Trágico de Machado de Assis: elementos para uma \\ pedagogia da escolha, by Rogério de Almeida
}

\section{ALMEIDA, Rogério de. $O$ imaginário trágico de Machado de Assis: elementos para uma pedagogia da escolha. São Paulo: Képos, 2015. 216 p.}

\section{Marcos Namba Beccari}

Universidade Federal do Paraná Curitiba, Paraná, Brasil

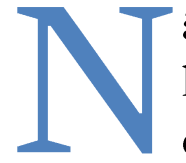
ão é inédita a ideia de que a obra machadiana, em sua configuração literária - portanto no imaginário ali arranjado -, expressa um determinado pensamento filosófico. O problema que acompanha historicamente essa ideia é antecipado por Hélio de Seixas Guimarães ${ }^{1}$ no prefácio de $O$ imaginário trágico de Machado de Assis: as tentativas de explicar filosoficamente o universo machadiano são "invariavelmente acompanhadas da intuição de que talvez não houvesse fundo nem explicação". Por conseguinte, como atesta Alfredo Bosi, ${ }^{2}$ "O que se tem até hoje como consenso é a qualificação da perspectiva de Machado de Assis por meio de epítetos negativos: cética, relativista, irônica, sardônica, sarcástica, pessimista, demoníaca".

Rogério de Almeida ${ }^{3}$ parte da hipótese de que essa negatividade não reside na obra machadiana, mas na recusa de alguns intérpretes ante a visão trágica de Machado: "não se trata de ignorar o trágico, mas de recusá-lo de partida, contornando-o onde se mostra demasiado evidente" ${ }^{4}$ Tal recusa se

\footnotetext{
${ }^{1}$ GUIMARÃES, Prefácio: uma leitura radical de Machado de Assis, p. 14.

${ }^{2}$ BOSI, Machado de Assis: o enigma do olhar, p. 11.

3 Professor livre-docente na Faculdade de Educação da USP. Trabalha com temas ligados à Antropologia do Imaginário, à Pedagogia da Escolha e à Filosofia Trágica. Escreveu, entre outros, $O$ criador de mitos: imaginário e educação em Fernando Pessoa (São Paulo: Educ, 2011).

${ }^{4}$ ALMEIDA, O imaginário trágico de Machado de Assis: elementos para uma pedagogia da escolha, p. 26. 
dá pela tentativa de acomodar o pensamento de Machado a uma intenção filosófica "maior", como a renúncia de cunho jansenista ou schopenhaueriana, uma crítica aos processos histórico-sociais ou mero "recalque" de uma vida marcada por sofrimento. Ocorre que

Machado, se disseca a moral, não é para corrigir os costumes; se trata da filosofia, não é para buscar a verdade; se aborda política, não é para se posicionar ideologicamente; se traz à tona as estruturas ósseas da sociedade, não é para indignar ou propor mudanças. ${ }^{5}$

Sendo assim, ou admitimos que não pode haver filosofia machadiana, ou repensamos a própria noção de filosofia. Não obstante, a filosofia trágica pode ser definida, entre outras coisas, como "antifilosofia", como oposto da intenção metafísica de conhecer e intervir numa suposta ordem ou princípio do que existe.

Ora, Machado de Assis zombava justamente de filosofias que, a pretexto de conhecer o que existe, debruçam-se sobre o que não existe: conceitos e sentidos que não se encontram em lugar algum. De modo análogo, a filosofia trágica começa por reconhecer que o mundo é insignificante, isto é, não possui sentido inerente. ${ }^{6}$ Se não possui sentido, não é interpretável, o que não impede de ser pensado: não cessamos de atribuir sentido a um mundo que é sem sentido. Essa ausência de sentido não implica que o mundo seja incompleto ou insuficiente; pelo contrário, implica que o mundo é completo em sua falta de sentido, não carece de nada - a exigência de sentido ocorre por "efeito" (humano, imaginário) e não como causa/necessidade.

É assim que o trágico da existência é tratado por autores historicamente tão díspares quanto Lucrécio, Montaigne, Hume, Nietzsche, Clément Rosset... e Machado de Assis. Com efeito, a interpretação inaugurada por Rogério de Almeida salienta o caráter trágico do imaginário machadiano. Expressão não de uma filosofia pessimista, niilista, transformadora ou lamentadora, e sim de uma filosofia trágica, que por sua vez não tem propriamente nada de "novo" a dizer, pois aquilo que mostra é o esforço humano de atribuir sentido a uma existência que prescinde de qualquer sentido.

\footnotetext{
${ }^{5}$ Idem, p. 24.

${ }^{6}$ Cf. ALMEIDA, Considerações sobre as bases de uma filosofia trágica; ROSSET, Lógica do pior; HIERRO, El saber trágico: de Nietzsche a Rosset.
} 
Não se trata de denunciar as ilusões humanas, e sim de tornar visível e exaltar o espetáculo de nossas significações imaginárias. Constatação de que o mundo é privado de sentido, mas também de que a intensidade dos sentidos imaginários engendra nossa maneira de viver no mundo. É essa intensidade que Rogério de Almeida enaltece ao pontuar que "a pior realidade por ele [Machado] imaginada vem sempre acompanhada de uma alegria estética arrebatadora". 7 Significa que Machado não apenas constata o trágico, mas principalmente que ele não desaprova o que constata - aprovação esta que constitui, de modo geral, o fio condutor do livro em questão.

O imaginário trágico de Machado de Assis é composto por sete capítulos, os quais são dispostos basicamente em três partes: (1) argumentação da filosofia trágica expressa no imaginário machadiano; (2) análises pontuais de elementos filosóficos presentes em peças selecionadas; (3) desdobramentos da literatura machadiana para a educação. Em constante diálogo com intérpretes da literatura machadiana - como Alfredo Bosi, Antonio Candido, Raymundo Faoro, João Adolfo Hansen, Alcides Villaça, entre outros -, Rogério de Almeida ancora-se na perspectiva nietzschiana de Clément Rosset e nos estudos da antropologia do imaginário de Gilbert Durand para explicitar a filosofia trágica que se expressa nas obras de Machado de Assis.

Essa tarefa é levada a cabo mais detidamente na análise cuidadosa (distribuída nos cinco capítulos que sucedem o primeiro) de contos como "Singular ocorrência", "O espelho", "A causa secreta" e "A cartomante", além do capítulo "O delírio" das Memórias póstumas de Brás Cubas. Uma vez delineada a expressão estética machadiana (como conjunção entre uma existência insignificante e a alegria de viver), Rogério de Almeida abre caminho, no último capítulo, a uma pedagogia da escolha, cujos elementos dizem respeito às escolhas possíveis em relação ao dado trágico da existência: sua aprovação incondicional (escolha trágica), sua recusa (suicídio) ou a imposição de condicionantes (ilusão).

Creio que é nesse peculiar direcionamento que reside a principal contribuição desse livro: uma educação machadiana como forma de aprender a desaprender. Se a educação está condicionada à crença em uma ou mais verdades - não é possível educar sem transmitir valores, conhecimentos, visões de mundo etc. -, a suspensão da crença derivada do imaginário machadiano pode ser vista como "antieducativa". No entanto, há algo aí sendo ensinado: "Aprende-se a ver e a considerar o que existe (aparência).

${ }^{7}$ ALMEIDA, cit., p. 79. 
Desaprende-se o que, desalojado da existência concreta, vai buscar uma ideia qualquer de totalidade e universalidade para explicar em conjunto o que sempre é singular e plural". ${ }^{8}$ Mais do que isso, esse horizonte trágico convoca à escolha da aprovação, isto é, a uma adesão incondicional da existência em todos os seus aspectos.

Donde a alegria machadiana "não se confunde com uma visão otimista, cândida ou serena de mundo. Pelo contrário, aparece justamente no que há de pior: no caráter insignificante da vida, eivada de dor e sofrimento". ${ }^{9}$ Eis o aspecto formativo que Rogério de Almeida destaca na literatura machadiana: nenhuma intenção pedagógica de transformação, mas de aprovação do momento vivido, das contradições, das mazelas, das convenções, das circunstâncias ao acaso e, enfim, de uma existência sem sentido.

\section{Referências}

ALMEIDA, Rogério de. Considerações sobre as bases de uma filosofia trágica. Diálogos Interdisciplinares, UBC, Mogi das Cruzes, v. 2, p. 52-63, 2013. Disponível em: http://www3.brazcubas.br/ojs2/index.php/dialogos/article/view/37. Acesso em: 8 set. 2015.

O imaginário trágico de Machado de Assis: elementos para uma pedagogia da escolha. São Paulo: Képos, 2015.

BOSI, Alfredo. Machado de Assis: o enigma do olhar. São Paulo: Martins Fontes, 2007.

GUIMARÃES, Hélio de Seixas. Prefácio: Uma leitura radical de Machado de Assis. In:

ALMEIDA, Rogério de. O imaginário trágico de Machado de Assis: elementos para uma pedagogia da escolha. São Paulo: Képos, 2015, p. 13-20.

HIERRO, Rafael Del. El saber trágico: de Nietzsche a Rosset. Madrid: Ediciones del Laberinto, 2001.

ROSSET, Clément. Lógica do pior. Rio de Janeiro: Espaço e Tempo, 1989.

MARCOS BECCARI é doutor em Educação pela USP, graduado em Design Gráfico e Mestre em Design, ambos pela UFPR. Atua como professor do Departamento de Design da UFPR e como pesquisador nos grupos: Navis - Núcleo de Artes Visuais (Unespar), Design Colaborativo e Cocriação (UFPR), Geifec - Grupo de Estudos sobre Itinerários de Formação em Educação e Cultura (FE-USP). Coautor do livro Existe design? Indagações filosóficas em três vozes (2AB, 2013). E-mail: contato@marcosbeccari.com.

Recebido: 09.09.2015

Aprovado: 19.10.2015

${ }^{8}$ Idem, p. 197.

${ }^{9}$ Idem, p. 204. 